\title{
Lymphocytic Infiltrations in the Lung of Two Autopsy Cases with HTLV-I-Associated Myelopathy
}

\author{
Katsunori SUGISAKI, Okifumi NAKAZATO, Tomiyasu TSUDA and Toru OKAJIMA
}

\begin{abstract}
Pulmonary involvement in two autopsy cases with HTLV-I-associated myelopathy (HAM) was observed histopathologically and immunohistochemically. Case 1 was a 59-year-old woman who fell ill after having a blood transfusion, and died immediately of acute heart failure. Case 2, a 55-year-old man, died of pelvic tumor after a long period of steroid medication for the myelopathy. Histologically, in case 1 , the submucosal stroma of bronchioles was thickened with T-lymphocyte infiltration. In addition, clusters of B-lymphocytes were aggregated beneath the epithelial layer of respiratory bronchiole; the alveolar septum was infiltrated with a few T-lymphocytes. Furthermore, many B-lymphocytes were aggregated in the submucosal stroma of large bronchi. On the other hand, obvious pathological changes were not seen in the lung tissues of case 2. The long period of steroid medication may account for the fewer findings in case 2 .

These results present the possibility that latent inflammatory changes develop in the lung of HAM patients, although clinical manifestations are not obvious, and that steroid therapy can modify those inflammatory changes.
\end{abstract}

Key words: $\quad$ HTLV-I infection, HAM, Lung disorder, Monoclonal antibody, Immunohistochemical study

HTLV-I-associated myelopathy (HAM) is a slowly progressive spastic paraparesis occurring in HTLV-I carriers, as reported by Osame et al in 1986 (1). Recently, Sugimoto et al revealed that Tlymphocytosis is frequently observed in the bronchoalveolar lavage fluid (BALF) of the patients with HAM (2). T-lymphocytosis in BALF has also been observed in HTLV-I-associated tropical spastic paraparesis (TSP), which is regarded to be the same disease as HAM (3). These findings suggest that a subclinical pulmonary disorder develops in the patients with HAM. In the present study, the pulmonary involvement was histopathologically investigated in two autopsy cases with HAM, and by using a monoclonal antibody method an attempt was made to determine whether the accumulated lymphocytes in the lesion were T-lymphocytes or B-lymphocytes.

\section{MATERIALS AND METHODS}

Patients: Case 1 was a 59-year-old woman who had blood transfusions during valvular replacement, due to mitral steno-insufficiency with aortic stenosis, in July, 1984. Six months later, she began complaining of gait disturbance and muscle weakness of the upper limbs. In June 1986, she was diagnosed to have HAM because of her progressive spastic paraparesis and the elevated antibody titers to HTLV-I in serum and CSF. She received steroid therapy for four wks and weakness of the upper limbs improved slightly. However, she died suddenly of congestive heart failure on July 19, 1986.

Case 2, a 55-year-old man, was admitted to our hospital in July 1985, because of gait disturbance. There was no history of blood transfusions, nor neurologic disorders in his family. For the myelitis of unknown etiology, steroid therapy (prednisolone)

From The Department of Medicine, Medical College of Oita, Oita

Received for publication October 16, 1989; Accepted for publication September 10, 1990

Reprint requests should be addressed to Katsunori Sugisaki, MD, The Department of Medicine,

Medical College of Oita, Hazama, Oita 879-55, Japan 
was started at the initial dose of $60 \mathrm{mg}$. Because the weakness of limbs was gradually improved, steroid therapy was continued at a dose of $20-30 \mathrm{mg}$. In July 1986, he was readmitted because of macrohematuria and was diagnosed to have a pelvic tumor. During this hospitalization, he was diagnosed to have HAM because of his progressive spastic paraparesis and the elevated antibody titers to HTLV-I in serum and CSF. The general condition worsened gradually, and he died of the tumor on July 21, 1987.

Both patients had no past history of lung disease and no pulmonary symptoms. The chest X-ray films of these patients showed no significant abnormalities (Fig. 1-A,B). Laboratory data on admission are listed in Table 1. Anti HTLV-I antibody titers were determined by the indirect immuno-fluorescence

(A)

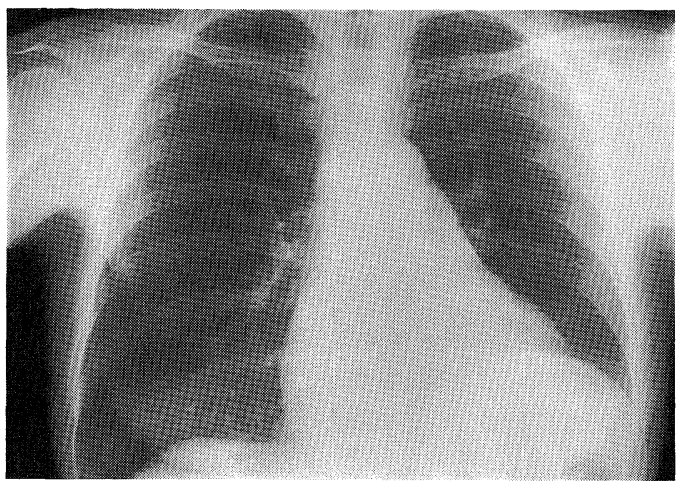

(B)

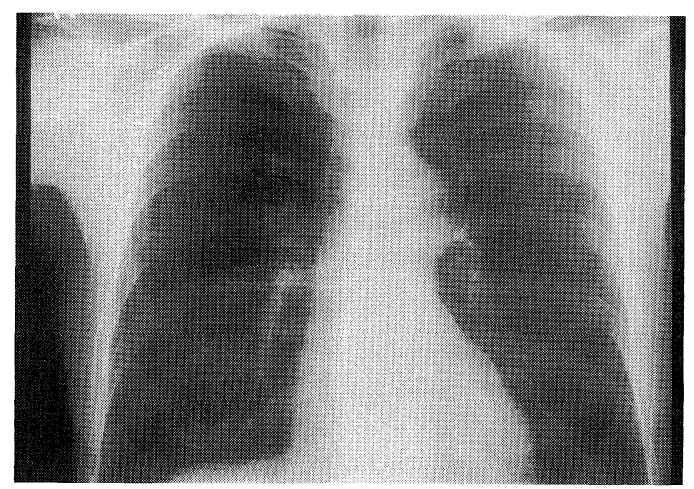

Fig. 1. A) Chest X-ray film of case 1 taken 1 yr before her death; her last film taken while standing. B) Chest X-ray film of case 2 taken 1 yr before his death; his last film taken while standing. Both films show no abnormal shadow in the lung fields.
Table 1. Laboratory findings on admission.

\begin{tabular}{|c|c|c|c|}
\hline \multicolumn{4}{|c|}{ Case $1(1986.4 .30)$} \\
\hline \multicolumn{2}{|c|}{ Urine } & \multicolumn{2}{|l|}{ Blood chemistry } \\
\hline Protein & $(-)$ & GOT & $22 \mathrm{IU} / 1$ \\
\hline Sugar & $(-)$ & GPT & $13 \mathrm{IU} / 1$ \\
\hline \multicolumn{2}{|c|}{ Peripheral blood } & $\mathrm{LDH}$ & $605 \mathrm{IU} / 1$ \\
\hline $\mathrm{RBC}$ & $377 \times 10^{4} / \mathrm{mm}^{3}$ & ALP & $159 \mathrm{IU} / \mathrm{l}$ \\
\hline $\mathrm{Hb}$ & $10.6 \mathrm{~g} / \mathrm{dl}$ & BUN & $10 \mathrm{mg} / \mathrm{ml}$ \\
\hline WBC & $4,360 / \mathrm{mm}^{2}$ & $\mathrm{Cr}$ & $0.6 \mathrm{mg} / \mathrm{ml}$ \\
\hline Neut & $41.8 \%$ & TP & $6.8 \mathrm{~g} / \mathrm{dl}$ \\
\hline Lym & $50.1 \%$ & \multicolumn{2}{|l|}{ Serological } \\
\hline Mo & $4.6 \%$ & CRP & $0.8 \mathrm{mg} / \mathrm{dl}$ \\
\hline $\mathrm{Ba}$ & $0.9 \%$ & \multicolumn{2}{|c|}{ Anti HTLV-I antibody titers } \\
\hline Eo & $1.2 \%$ & in serum & $\times 1,280$ \\
\hline PLT & $25.3 \times 10^{4} / \mathrm{mm}^{3}$ & in spinal fluid & $\times 64$ \\
\hline \multicolumn{4}{|c|}{ Case 2 (1986.7.18) } \\
\hline \multicolumn{2}{|c|}{ Urine } & \multicolumn{2}{|l|}{ Blood chemistry } \\
\hline Protein & $(-)$ & GOT & $11 \mathrm{IU} / 1$ \\
\hline Sugar & $(-)$ & GPT & $6 \mathrm{IU} / 1$ \\
\hline \multicolumn{2}{|c|}{ Peripheral blood } & $\mathrm{LDH}$ & $628 \mathrm{IU} / 1$ \\
\hline $\mathrm{RBC}$ & $437 \times 10^{4} / \mathrm{mm}^{3}$ & ALP & $137 \mathrm{IU} / 1$ \\
\hline $\mathrm{Hb}$ & $12.1 \mathrm{~g} / \mathrm{dl}$ & BUN & $19 \mathrm{mg} / \mathrm{dl}$ \\
\hline WBC & $7,840 / \mathrm{mm}^{3}$ & Cre & $1.1 \mathrm{mg} / \mathrm{ml}$ \\
\hline Neut & $72.5 \%$ & $\mathrm{TP}$ & $6.4 \mathrm{~g} / \mathrm{dl}$ \\
\hline Lym & $20 \%$ & \multicolumn{2}{|l|}{ Serological } \\
\hline Mo & $6.2 \%$ & CRP & $1.6 \mathrm{mg} / \mathrm{dl}$ \\
\hline $\mathrm{Ba}$ & $0.5 \%$ & \multicolumn{2}{|c|}{ Anti HTLV-I antibody titers* } \\
\hline Eo & $0.4 \%$ & in serum & $\times 5,120$ \\
\hline PLT & $36 \times 10^{4} / \mathrm{mm}^{3}$ & in spinal fluid & $\times 10$ \\
\hline
\end{tabular}

* Anti HTLV-I antibody titers were determined by the indirect immuno-fluorescence method (4)

method (4) in this study.

Specimens: Tissues were obtained from the autopsied lungs of these patients and fixed in $20 \%$ formaldehyde. Specimens were sampled from the peripheral areas of each lobe and from two central areas along the right lower bronchus.

Immunohistochemical studies: Immunohistochemical stain with monoclonal antibodies was performed in order to identify the lymphocyte subtype in the various lesions of the lungs using the biotinavidin-horseradish peroxidase system (5). Briefly, deparaffinized tissue sections were treated for 20 min in a mixture of $0.5 \% \quad \mathrm{H}_{2} \mathrm{O}_{2}$ and $50 \%$ methanol to block endogenous peroxidase activity. After the block of nonspecific reactions with normal human $\mathrm{AB}$ serum, the sections were reacted for 1 $h$ with anti-T-lymphocyte monoclonal antibody (MT-1) and anti-B-lymphocyte monoclonal antibody (MB-1) (Bio-Science, Emmenbrucke, Switzerland) at $4^{\circ} \mathrm{C}$. Biotinylated anti-mouse $\operatorname{IgG}$ and avidin- 
biotinylated horseradish peroxidase complexes (Lipshaw, Detroit, MI) were reacted in that order. After the development of the peroxidase activity with 3-amino-9-ethylcarbazole and $0.01 \% \quad \mathrm{H}_{2} \mathrm{O}_{2}$, Tlymphocytes and B-lymphocytes were determined in the tissues.

\section{RESULTS}

Light microscopic findings: In case 1, lymphocyte infiltrations were observed in various lesions of the broncho-pulmonary systems. Lymphocyte infiltration was seen around the mucous glands in the submucosal connective tissues of the large bronchi with cartilage. Some conglomerations of lymphocytes

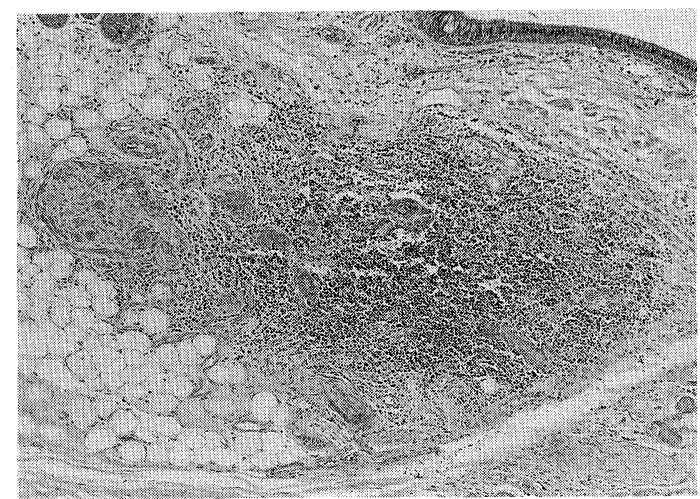

Fig. 2. The large bronchus of case 1. Infiltration of numerous mononuclear cells is seen around the atrophied or degenerated mucous glands in the submucosal connective tissue (hematoxylin-eosin, original magnification $\times 25)$.

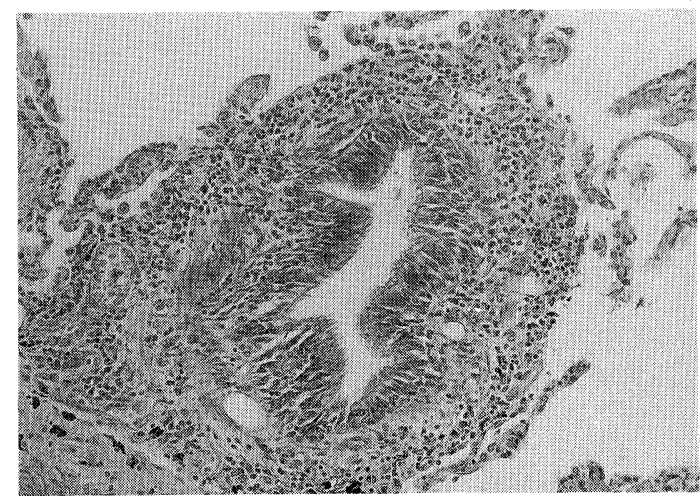

Fig. 3. Submucosal layer of membranous bronchiole of case 1 showing collagenous thickening with infiltration of numerous mononuclear cells (hematoxylin-eosin, original magnification $\times 50$ ). contained a few atrophied or degenerated mucous glands (Fig. 2). The submucosal connective tissues of membranous bronchioles showed collagenous thickening and mononuclear cell infiltration (Fig. 3). Also in the respiratory bronchioles, lymphocyte infiltration was seen frequently in the thickened submucosal connective tissues. Some lymphocyte clusters were formed as lymphoid follicles beneath the cuboidal epithelial layer of the respiratory bronchioles (Fig. 4). In the alveoli, a few lymphocytes infiltrated mainly around the venules. However, obvious thickening of the alveolar septa was not observed (Fig. 5). Those pathological changes were observed in all tissue sections of case

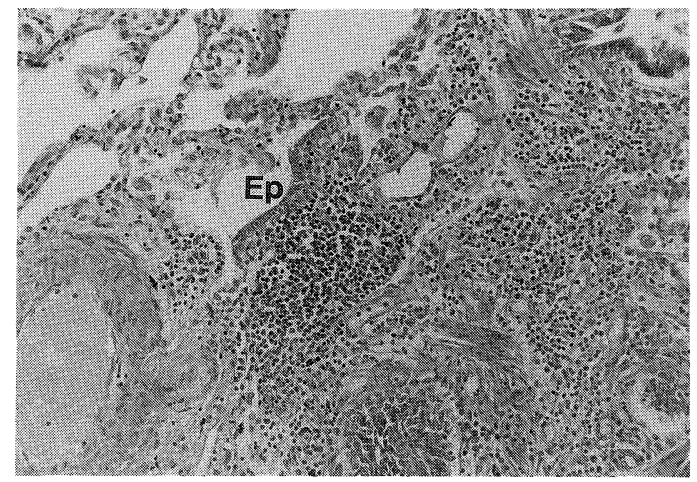

Fig. 4. The respiratory bronchiole of case 1 showing numerous mononuclear cells infiltrating the submucosal layer, some of which form a cluster beneath the epithelium of the respiratory bronchiole (Ep). Submucosal layer shows prominent thickening (hematoxylin-eosin, original magnification $\times 50$ ).

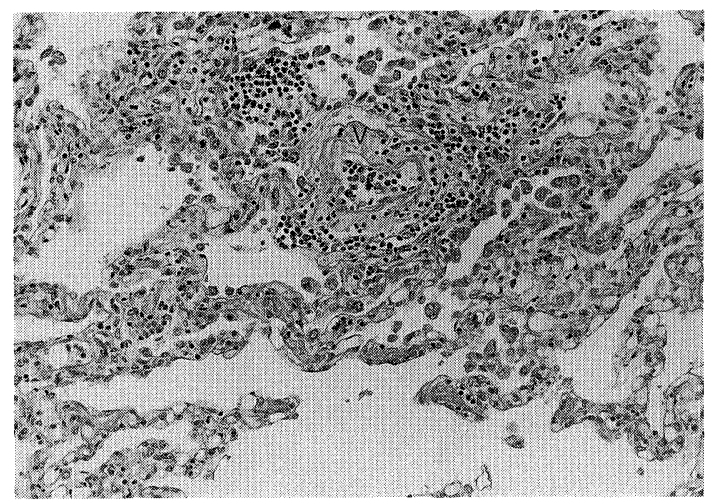

Fig. 5. The alveolus of case 1 showing a few mononuclear cells infiltrating the area around the venule (V). The wall of the venule shows edematous thickening (hematoxylin-eosin, original magnification $\times 50$ ). 
1. Obvious atypical lymphocytes were not seen in any lesions.

On the other hand, in the lung of case 2, pathological findings were not so obvious. Also in the spinal cord, mononuclear cell infiltration was not so prominent.
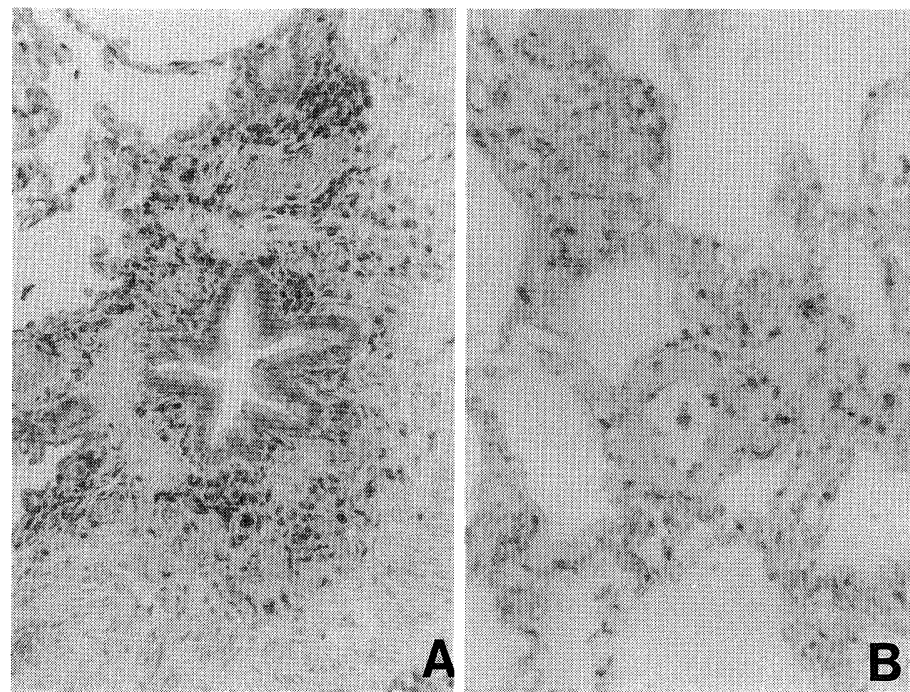

Fig. 6. Immunohistochemical staining with anti-T-lymphocyte monoclonal antibody (MT-1). A) The membranous bronchiole of case 1. Numerous MT-1 positive cells infiltrate the submucosal layer. B) The alveolus of case 1. MT-1 positive cells are scattered in the venule and in the surrounding alveolar septum (immunoperoxidase stain, hematoxylin counterstain, original magnification $\times 50)$.
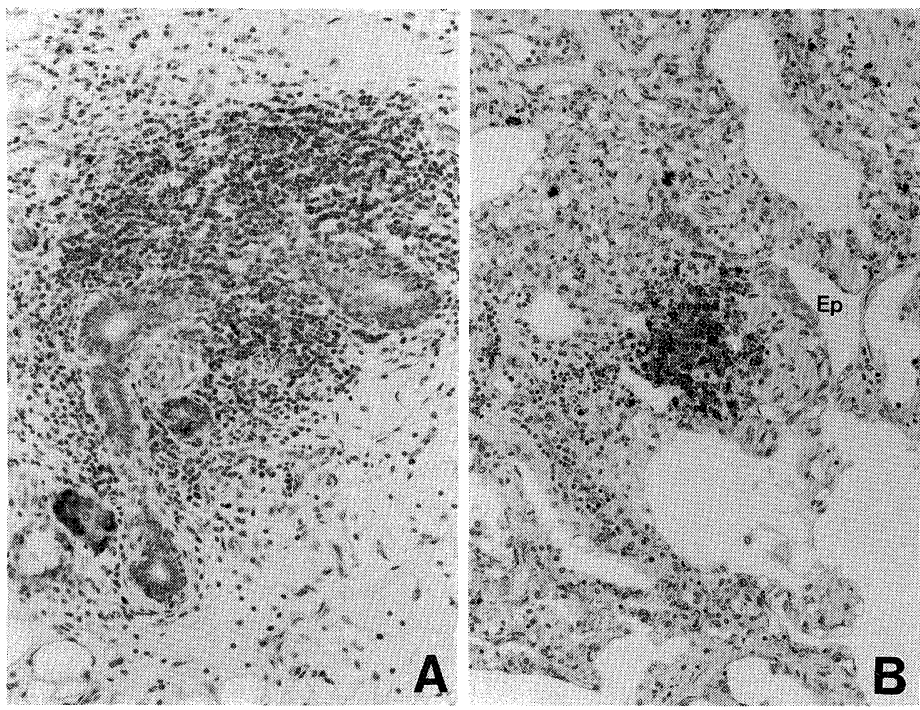

Fig. 7. Immunohistochemical staining with anti-B-lymphocyte monoclonal antibody (MB-1). A) The large bronchus of case 1. Most of the lymphocytes accumulating around the atrophied mucous glands are positive to MB-1. B) The respiratory bronchiole of case 1. MB-1-positive cells form a cluster beneath the epithelial layer $(\mathrm{Ep})$ of the respiratory bronchiole (immunoperoxidase stain, hematoxylin counterstain, original magnification $\times 50$ ). 
Immunohistochemical findings: Immunohistochemical staining with MT-1 revealed that the Tlymphocytes were diffusely infiltrated in the lung tissues of case 1. Many T-lymphocytes infiltrated the submucosal stroma of the membranous bronchioles (Fig. 6-A). A few T-lymphocytes were scattered in the alveolar septa around the venules (Fig. 6-B). Immunohistochemical staining with MB-1 revealed that B-lymphocytes formed clusters as lymphoid follicles in case 1 . These cluster formations of Blymphocytes were seen around the mucous glands in the submucosal connective tissues of the central bronchi and beneath the epithelial layer of the respiratory bronchiole (Fig. 7-A,B).

\section{DISCUSSION}

HTLV-I-associated myelopathy (HAM) is a spastic paraparesis occurring in HTLV-I carriers, but the underlying mechanism responsible for the clinical manifestations still remains unclear. The autopsy findings of the two cases presented here have already been described by Akizuki et al $(6,7)$ with a special reference to the spinal lesions. Case 1 probably contracted the disease acutely through the blood transfusion, and had received steroid therapy for a short period of time before death. In contrast, case 2 suffered from chronic development of the disease which was possibly contracted vertically through the familial line and had received steroid therapy for a long period of time. The fact that the two cases were considerably different in the pathological pictures of the lungs can be explained by the difference in disease progression and treatment as described above. Thus, in the former case it was observed that the Tlymphocytes had infiltrated primarily around the bronchioles, while the B-lymphocytes were clustered characteristically around the respiratory bronchioles and around the mucous glands in the submucosal layers of large bronchi. In case 2, on the other hand, not so obvious pathological findings were found. Sugimoto et al (2) found by bronchoalveolar lavage that the lung of HAM patients was frequently complicated with T-lymphocytosis. Similar findings have also been reported in the case of tropical spastic paraparesis (TSP) which has been thought to share the same pathological manifestation (3). It was also demonstrated from the pathological observation of the lungs of patients with acquired immunodeficiency syndrome (AIDS) - related pneumonitis (8) or of lentiviral chronic pneumonia of a certain animal (9) that the lymphocytes are widely disseminated throughout the lungs from the alveolar septa to the bronchi, and that germinal centers are formed in the interstitium between adjacent alveolar walls. The present observations in case 1 present the possibility that latent inflammatory changes develop in the lung of HAM patients. The pathological picture of the lungs of case 2 was significantly milder than that of case 1 . This can might be explained by the possibility that the inflammatory changes in case 1 were reserved intactly because of sudden death with short period of steroid medication. On the other hand, the pathologic processes of case 2 were modified because of having received steroid therapy for a long time and the chemotherapy for the pelvic tumor, and caused wide deviation in appearance. Indeed, Akizuki et al pointed out that lymphocyte infiltration associated with spinal lesions was considerably meager in case 2 (7). Sustained administration of steroid may resolve the chronic inflammation associated with HAM, thereby leading to remission of the disease. In addition, it may be considered that the case suffered from blood transfusion has more prominent lymphocytes infiltrations than a patient contracting the disease by vertical infection through the familial line.

It should be noted that rather conspicuous inflammatory changes were seen surrounding the respiratory bronchioles in case 1 . In addition to $\mathrm{T}$ lymphocyte infiltration, cluster formation of $\mathrm{B}$ lymphocytes beneath the epithelial layer was observed, along with hypertrophy of the submucosal connective tissue. The respiratory bronchioles are thought to be one of the weak points of the lung when considering as a preventive barrier against external pathogens. Thus, if the inflammation of bronchioles persisted, it would extend to adjacent alveoli, and may result in an appearance of clinical manifestation in the long run. Kimura et al suggested that chronic infection by HTLV-I might be involved in some way in the development of diffuse panbronchiolitis (DPB) (10). This is quite interesting in view of the fact that HAM patients have prominent 
lesions on the respiratory bronchioles.

The details of the pathological mechanisms causing the chronic inflammation observed in the lung of HAM and TSP patients still remain obscure. However, Maruyama et al recently reported that T-lymphocytes in BALF obtained from HAM patients show a specific reaction to HTLV-I, functioning as an antigen (11). This strongly suggested that the T-lymphocytes which infiltrate the lung are sensitized to HTLV-I. In the present case 1, Blymphocytes were also observed to be aggregated around the respiratory bronchioles and mucous glands. So, sensitized T-lymphocytes may mediate the $\mathrm{B}$ cell accumulation and activation for the production of specific antibody to HTLV-I in the lung of HAM patients. In AIDS patients, alveolar macrophages are thought to be infected with HIV, suggesting that they act as a reservoir for HIV (12). However, in HAM, it has been unknown which cells are infected by HTLV-I and become the target of sensitized $\mathrm{T}$ lymphocytes.

In the present observations, latent pulmonary involvement was shown histologically in the lung tissues of HAM patients. An interesting problem for the future will be to elucidate whether such latent chronic inflammatory changes as observed in case 1 exist in the lung of other HAM patients and whether these changes cause the overt bronchial inflammation with complicated infections.

ACKNOWLEDGMENTS: The authors wish to thank Dr. Kazuro Iwai for the helpful suggestions in the interpretation of the histopathological findings.

\section{REFERENCES}

1) Osame M, Usuku K, Izumo S, et al. HTLV-I associated myelopathy, a new clinical entity. Lancet i: 1031, 1986.

2) Sugimoto $M$, Nakashima $H$, Watanabe $S$, et al.
T-lymphocyte alveolitis in HTLV-I associated myelopathy. Lancet ii: 1220, 1987.

3) Couderc LJ, Caubarrere I, Venet A, et al. Lymphocytic alveolitis in HTLV-I-associated tropical spastic paraparesis. in: HTLV-I and the Nervous System, Alan R. Liss, Inc, New York, 1988, p.457.

4) Hinuma $Y$, Nagata $K$, Hanaoka $M$, et al. Adult T-cell leukemia: Antigen in an ATL cell line and detection of antibodies to the antigen in human sera. Proc Natl Acad Sci USA 78: 6476, 1981.

5) Sternberger LA, Hardy PH Jr, Cuculis JJ, Meyer HG. The unlabeled antibody-enzyme method of immunohistochemistry. Preparation and properties of soluble antigen-antibody complex (horseradish peroxidaseantihorseradish peroxidase) and its use in identification of spirochetes. J Histochem Cytochem 18: 315, 1970.

6) Akizuki S, Nakazato O, Higuchi Y, et al. Necropsy findings in HTLV-I associated myelopathy. Lancet i: 156, 1987.

7) Akizuki S, Yoshida S, Setoguchi $M$, et al. The neuropathology of human T-lymphotropic virus type I-associated myelopathy. in: HTLV-I and the Nervous System, Alan R. Liss, Inc, New York, 1988, p.253.

8) Solal-Ceigny $P$, Couderc LJ, Herman $D$, et al. Lymphoid interstitial pneumonitis in acquired immunodeficiency syndrome-related complex. Am Rev Respir Dis 131: 956, 1985.

9) Narayan O, Cork LC. Lentiviral disease of sheep and goats: Chronic pneumonia leukoencephalomyelitis and arthritis. Rev Infect Dis 7: 89, 1985.

10) Kimura I, Tsubota $T$, Tada $S$, et al. Presence of antibodies against adult $\mathrm{T}$ cell leukemia antigen in the patients with chronic respiratory disease. Acta Med Okayama 40: 281, 1986.

11) Maruyama I, Sakashita I, Mori S, et al. Pulmonary involvement in HTLV-I-associated myelopathy: T-cell accumulation in the lung and cellular hyperimmune responsiveness against HTLV-I. in: HTLV-I and the Nervous System, Alan R. Liss, Inc, New York, 1988, p.471.

12) Salahuddin SZ, Rose RM, Groopman JE, Markham PD, Gallo RC. Human T lymphotropic virus type III infection of human alveolar macrophages. Blood 68: $281,1986$. 